\title{
FITOTOXIDEZ E TROCAS GASOSAS NA MANDIOCA SUBMETIDA A APLICAÇÃO DE MISTURAS DE HERBICIDAS EM PÓS EMERGÊNCIA
}

\section{FITOTOXIDITY AND GAS EXCHANGES IN THE MANDIOCA SUBMITTED THE APPLICATION OF MIXTURES OF HERBICIDES AFTER EMERGENCY}

\author{
Alessandro da Costa Lima ${ }^{1}$; Leandro do Rosário Silva ${ }^{2}$; Vicente Bezerra Pontes ${ }^{3}$; Ana Clara \\ Moura de Sousa ${ }^{4}$; Rafael Gomes Viana ${ }^{5}$
}

DOI: https://doi.org/10.31692/978-65-991061-7-0.439-444

\section{INTRODUÇÃ̃O}

A mandioca (Manihot esculenta Crantz) é um arbusto perene, da família Euphorbiaceae, com raízes tuberosas ricas em amido (ALVES, 1990). É uma das principais fontes de alimentação para grande parte da população nas regiões Norte e Nordeste, destacando-se sua importância social, cultural e econômica (ALVES \& MODESTO JÚNIOR, 2012). O potencial produtivo da cultura pode chegar a mais de 100 toneladas $/ \mathrm{ha}^{-1}$, entretanto a produtividade média da mandioca na região norte em 2017 foi de 15,3 toneladas/ha-1 (IBGE, 2018). Um dos principais gargalos na cadeia produtiva está relacionado ao controle de plantas daninhas, que são responsáveis por grandes perdas de produtividade. As plantas daninhas são pragas infestantes com alta capacidade competitiva, prejudicando a absorção de água, luz e nutrientes por parte da planta de interesse e seu controle pode representar até $45 \%$ do custo total da produção da mandioca (LORENZI \& DIAS, 1993). O manejo integrado é uma ferramenta eficiente para o controle dessas pragas, utilizando-se técnicas como o controle químico. O aumento no espectro de controle pode ser feito através da utilização de diferentes mecanismos de ação na mistura de herbicidas em tanque. Entretanto, essa prática pode resultar em antagonismo, perda de seletividade e outros problemas para a cultura, sendo necessário realizar os devidos testes para que se possa utilizar com maior segurança e eficiência na cultura da mandioca. Tendo em vista a importância da cultura e a falta de informações a respeito da mistura de herbicidas para a mandioca, objetivou-se avaliar a fitotoxidez e trocas gasosas na mandioca submetida a aplicação de misturas de herbicidas em pós emergência.

\footnotetext{
${ }^{1}$ Agronomia, Universidade Federal rural da Amazônia, alelima.agro@ gmail.com

2 Agronomia, Universidade Federal rural da Amazônia, leandrorsilva65@gmail.com

${ }^{3}$ Agronomia, Universidade Federal rural da Amazônia, vicente.pontes94@gmail.com

${ }^{4}$ Agronomia, Universidade Federal rural da Amazônia, claramsousa123@gmail.com

${ }_{5}^{5}$ Professor Doutor, Universidade federal Rural da Amazônia, Instituto de Ciências Agrárias, rafael.gomes@ufra.edu.br
} 


\section{FUNDAMENTAÇÃO TEÓRICA}

Em trabalho sobre características fotossintéticas de cultivares de mandioca tratadas com fluazifop-p-butyl e fomesafen, Silveira et al (2012) observaram que a mistura dos herbicidas provocou incrementos na quantidade de $\mathrm{CO}_{2}$ consumida, concentração de $\mathrm{CO}_{2}$ na câmara subestomática e na taxa fotossintética dos cultivares avaliados.

Resultados obtidos por Oliveira Jr (1994) e Oliveira Jr. et al., (1995) indicam que a resposta da mandioca à aplicação de herbicidas varia desde a total seletividade até o completo comprometimento da produção, por causa da toxicidade provocada à cultura

\section{METODOLOGIA}

O experimento foi realizado no campo experimental da Fazenda Escola de CastanhalPA, da Universidade Federal Rural da Amazônia. Com delineamento experimental de blocos ao acaso, em arranjo fatorial $5 \times 4$, que corresponde a 5 tratamentos (2 controles e 3 combinações de herbicidas) com 4 repetições. Os tratamentos constituíram-se pela combinação de 4 herbicidas aplicados em mistura de tanque (Fluasifope-P-Butílico, Metsulfurom Metílico, Isoxaflutol, Flumioxazina). A dose dos produtos foi de acordo com sua recomendação na bula. No total, os tratamentos avaliados foram: 1-Capina mecânica (Limpo); 2-Sem controle de plantas daninhas (Sujo); 3- Fluasifope-P-Butílico + Metsulfurom Metílico; 4- Fluasifope-P-Butílico + Isoxaflutol; 5- Fluasifope-P-Butílico + Flumioxazina. A tabela 1 demonstra as doses aplicadas em cada tratamento.

Tabela 1 - Tratamentos e doses utilizadas.

\begin{tabular}{cc}
\hline TRATAMENTO & DOSE \\
Limpo & g de i.a em equivalente ha $^{-1}$ \\
Sujo & 0 \\
Fluasifope-P-Butílico + Metsulfurom Metílico & 0 \\
Fluasifope-P-Butílico + Isoxaflutol & $250+3$ \\
Fluasifope-P-Butílico + Flumioxazina & $250+93,75$ \\
\hline
\end{tabular}

A área foi preparada em sistema convencional com duas arações e uma gradagem niveladora. O plantio de mandioca da cultivar BRS Poti, foi realizado com o uso de plantadeira mecanizada no espaçamento entre linhas de $0,9 \mathrm{~m}$ e aproximadamente $1,0 \mathrm{~m}$ entre plantas, promovendo densidade de 11.111 plantas ha $^{-1}$. De acordo com a análise do solo não foi necessário realizar calagem e adubação fosfatada, apenas adubação potássica com aplicação de cloreto de potássio $\left(100 \mathrm{~kg} \mathrm{ha}^{-1}\right)$ e nitrogenada com uréia $\left(89 \mathrm{~kg} \mathrm{ha}^{-1}\right)$ parcelados aos 30, 70 e 110 dias após o plantio (DAP). A aplicação dos tratamentos ocorreu aos 30 dias 
após emergência com pulverizador pressurizado a $\mathrm{CO}_{2}$, velocidade de $4 \mathrm{~km} \mathrm{~h}^{-1}$ e pressão de $50 \mathrm{lib} \mathrm{pol}^{-2}$ em barra de $50 \mathrm{~cm}$ munida de duas pontas de pulverização de duplo leque AD-IA 11002 e $100 \mathrm{~L} \mathrm{ha}^{-1}$ de volume de calda.

Trinta dias após a aplicação (DAA) dos tratamentos foram realizadas, entre 9 e $12 \mathrm{~h}$ da manhã, as avaliações na primeira folha completamente desenvolvida do terço médio das plantas. Utilizando um analisador de gases no infravermelho (modelo LI-6400XT da LICOR), em níveis constantes de luz $\left(1000 \mu \mathrm{mol} \mathrm{m} \mathrm{m}^{-2} \mathrm{~s}^{1}\right)$ e $\mathrm{CO}_{2}(400 \mu \mathrm{mol})$, foi avaliada a taxa de assimilação líquida de $\mathrm{CO}_{2}\left(\mathrm{~A}-\mu \mathrm{mol} \mathrm{m} \mathrm{m}^{-2} \mathrm{~s}^{-1}\right)$, condutância estomática ao vapor d'água $(\mathrm{gS}$ mol m $\left.\mathrm{m}^{-1} \mathrm{~s}^{-1}\right)$, taxa de transpiração $\left(\mathrm{E}-\mathrm{mol} \mathrm{H}_{2} \mathrm{O} \mathrm{m}^{-2} \mathrm{~s}^{-1}\right)$ e temperatura foliar $\left(\mathrm{TF}{ }^{\circ} \mathrm{C}\right)$. Também foram realizadas análises biométricas com diâmetro do caule e altura da planta. $\mathrm{O}$ efeitos do herbicida sobre a cultura da mandioca e nas plantas daninhas foram avaliados aos 30 DAA, de acordo com os sintomas visuais de fitotoxicidade, numa escala de 0 (zero) a $100 \%$, em que 0 (zero) equivale a nenhum dano visível na planta e 100 à morte da planta (FRANS, 1972). Foi realizada análise de variância e as médias comparadas pelo teste de Tukey a $5 \%$ de probabilidade.

\section{RESULTADOS E DISCUSSÕES}

$\mathrm{Na}$ análise de fitotoxidez (Figura - 1), os tratamentos Fluasifope+Metsulfurom e Fluasifope+Isoxaflutol não diferiram entre si, apresentando injúrias acima de 50\% na cultura da mandioca e menos que 50\% nas plantas daninhas, demonstrando ineficiência no espectro de controle e seletividade à cultura. Segundo Silva \& Silva (2003), a mistura de inibidores da ACCase+Sulfoniluréias (Fluasifope+Metsulfurom) pode apresentar antagonismo, provavelmente por afetar a absorção foliar. A mistura de Fluasifope+Isoxaflutol foi ineficiente, provavelmente pelo efeito do isoxaflutol na inibição da síntese de carotenoides, levando perda da clorofila por sua oxidação pela luz (MORELAND, 1980).

Já o tratamento Fluasifope+Flumioxazina apresentou danos de $25 \%$ na cultura da mandioca e de $100 \%$ nas plantas daninhas, tendo um espectro de controle muito eficiente e uma boa seletividade para a cultura. Os efeitos típicos da flumioxazina, descritos por WELLER (2003c), não foram observados na mandioca. Entretanto, ocorreu efeito sinérgico no controle de plantas daninhas quando misturado ao Fluasifope-P-Butílico. 
Figura 1 - Índices de fitotoxidade na mandioca e plantas daninhas (PDs) submetidas a aplicação de diferentes combinações de herbicidas. F+M: Fluasifope+metsulfuron; F+I: Fluasifope+Isoxaflutol; F+Flu:

Fluasifope+Flumioxazina Fonte: Própria.

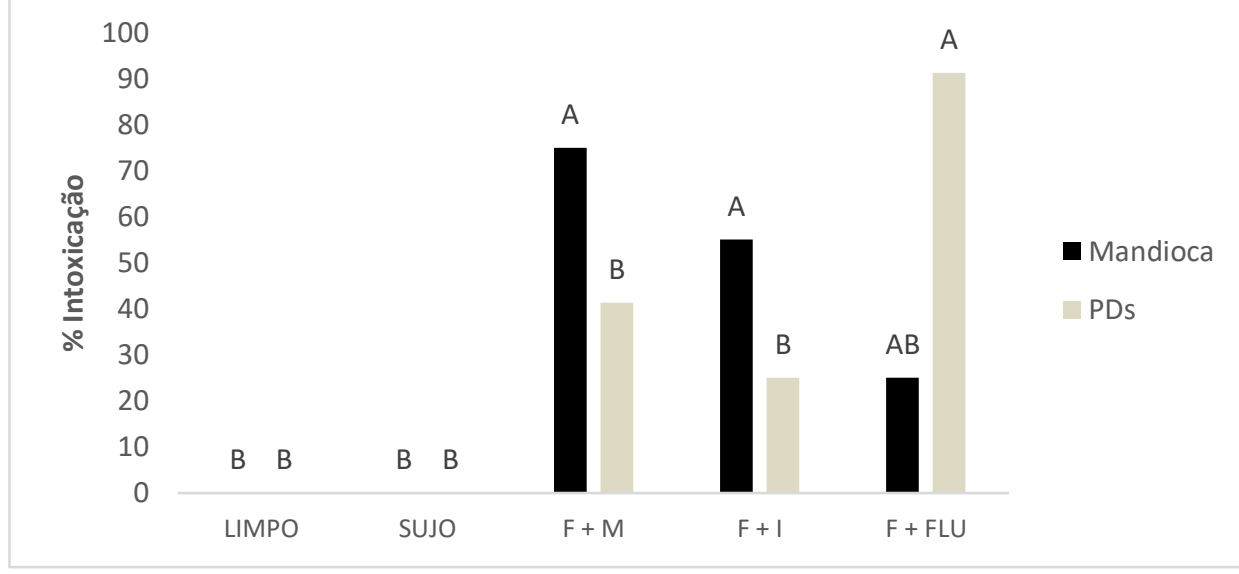

Os resultados de trocas gasosas (Tabela - 2) apontam que o tratamento Fluasifope+Flumioxazina obteve os melhores resultados, porém sem se diferenciar do tratamento Fluasifope+Isoxaflutol, no que se refere à taxa de assimilação líquida de $\mathrm{CO}_{2}$, condutância estomática ao vapor d'água, taxa de transpiração e temperatura foliar. Estes resultados indicam que a mistura Fluasifope+Flumioxazina não prejudicou as trocas gasosas da planta, possibilitando até mesmo um aumento quando comparada às testemunhas, provavelmente, pelo eficiente controle das plantas daninhas, diminuindo a competição por água, luz e nutrientes pela cultura.

Tabela 2 - Altura, diâmetro, taxa de assimilação líquida de $\mathrm{CO}_{2}(\mathrm{~A})$, condutância estomática ao vapor d'água $(\mathrm{gS})$, taxa de transpiração (E) e temperatura foliar $\left(\mathrm{TF}^{\circ} \mathrm{C}\right)$ de mandioca submetida a aplicação de mistura de herbicidas em pós emergência.

\begin{tabular}{|c|c|c|c|c|c|c|}
\hline Tratamento & Altura $^{\text {ns }}$ & Diâmetro $^{\text {ns }}$ & $\begin{array}{c}\text { A } \\
\mu \mathrm{mol} \mathrm{m} \mathrm{m}^{-2} \mathrm{~s}^{-1}\end{array}$ & $\begin{array}{c}\mathrm{gS} \\
\mathrm{mol} \mathrm{m}^{-1} \mathrm{~s}^{-1}\end{array}$ & $\begin{array}{c}\mathrm{E} \\
\mathrm{mol}_{2} \mathrm{O} \mathrm{m}^{-2} \mathrm{~s}^{-1}\end{array}$ & $\mathrm{TF}^{\circ} \mathrm{C}$ \\
\hline Limpo & 27,27 & 8,75 & $27,00 \mathrm{ab}$ & 0,20ab & $32,79 \mathrm{ab}$ & $32,7 b$ \\
\hline Sujo & 31,38 & 9,57 & $25,10 \mathrm{ab}$ & $0,18 \mathrm{ab}$ & $33,36 a b$ & $33,3 \mathrm{a}$ \\
\hline $\begin{array}{l}\text { Fluasifope+ } \\
\text { Metsulfurom }\end{array}$ & 24,22 & 7,56 & $8,82 b c$ & $0,07 b c$ & $34,01 b c$ & $34,0 \mathrm{a}$ \\
\hline $\begin{array}{c}\text { Fluasifope }+ \\
\text { Isoxaflutol }\end{array}$ & 28,53 & 9,26 & $27,55 \mathrm{a}$ & $0,23 \mathrm{a}$ & $34,61 \mathrm{a}$ & $34,6 a$ \\
\hline $\begin{array}{c}\text { Fluasifope }+ \\
\text { Flumioxazina }\end{array}$ & 24,85 & 7,76 & $30,70 \mathrm{a}$ & $0,24 \mathrm{a}$ & $34,15 \mathrm{a}$ & $34,1 \mathrm{a}$ \\
\hline
\end{tabular}

No tratamento Fluasifope+Isoxaflutol, os bons resultados nas trocas gasosas podem ter sido causados pois a mistura apesar de causar grande dano nos tecidos novos da planta, não causou danos imediatos às folhas já formadas. Entretanto, mediante a necessidade de 
renovação dos carotenoides, os parâmetros gasosos tendem a decair quando o efeito do isoxaflutol agir nas folhas velhas (HESS \& BRIDGES, 2003).

O tratamento Fluasifope+Metsulfurom, apresentou os piores resultados para os parâmetros avaliados, como no caso da taxa de assimilação de $\mathrm{CO}_{2}$ e a condutância estomática. Entretanto, a taxa de transpiração apresentou maior valor em comparação aos demais tratamentos. Isso pode indicar que os estômatos estão abertos, mas a planta não está exercendo boa atividade fotossintética, devido a clorose de folhas novas e a necrose de tecidos, o que ocorre entre sete e quatorze dias após a aplicação, apesar da interrupção no crescimento das plantas e a morte das regiões meristemáticas ocorrerem logo após a aplicação (Rodrigues \& Almeida, 2011).

\section{CONCLUSÕES}

As misturas não afetaram os parâmetros biométricos de altura e diâmetro. A mistura Fluasifope+Flumioxazina promoveu maior controle de plantas daninhas, menor fitotoxidez na mandioca e maior trocas gasosas.

\section{REFERÊNCIAS}

ALVES, A. A. C. Fisiologia da mandioca. Cruz das Almas: EMBRAPA-CNPMF, 1990.

ALVES, R.N.B; MODESTO JÚNIOR, M.S. Roça sem fogo e trio da produtividade da mandioca. Inclusão Social, Brasília, v. 6 n. 1, p.191-200, 2012.

BRASIL, IBGE. Levantamento Sistemático da Produção Agrícola, 2017. Disponível em < https://sidra.ibge.gov.br/tabela/188> Acesso em: 16/10/2018.

HESS, F. D.; BRIDGES, D. Mode of action of carotenoid biosynthesis inhibitors. In: Herbicide action course. West Lafayette: Purdue University, 2003. p. 383-396.

LORENZI, J.O. \&; DIAS, C. A. C. Cultura da mandioca. Campinas, SAA/CATI, 1993. 41p. (Boletim técnico, 211)

MORELAND, D. E. Mechanisms of action of herbicides. Annual review. Plant Physiology, Rockville, 1980, p. 610.

OLIVEIRA Jr., R.S. Seletividade e eficiência de trifluralin e diuron aplicados em diferentes formas na cultura da mandioca (Manihot esculenta Crantz). R. Unimar, v.16, n.2, p.317- 325, 1994.

OLIVEIRA Jr., R.S.; ZOTARELLI, L.; HIRAI, L.T. Seletividade e eficiência de controle de clethodim na fase inicial de desenvolvimento da cultura da mandioca. In: CONGRESSO BRASILEIRO DE HERBICIDAS E PLANTAS DANINHAS, 20, 1995, Florianópolis-SC. 
Resumos... Florianópolis: SBCPD, 1995. p.166-167.

SILVA, A. A.; SILVA, J. F. Tópicos em manejo de plantas daninhas. Viçosa, MG: Universidade Federal de Viçosa, 2003.

SILVA, A. A.; SILVA, J. F. (Eds.). Tópicos em manejo de plantas daninhas. Viçosa, MG: Universidade Federal de Viçosa, 2003.

RODRIGUES, B.N.; ALMEIDA, F.S. Guia de herbicidas. 6.ed. Londrina, 2011. 667p

SILVEIRA, Hellen Martins da et al. Características fotossintéticas de cultivares de mandioca tratadas com fluazifop-p-butyl e fomesafen. REVISTA AGRO@MBIENTE ON-LINE, [S.1.], v. 6, n. 3, p. 222-227, dec. 2012. ISSN 1982-8470

WELLER, S. Principles of selective weed control with herbicides. In: Herbicide action course. West Lafayette: Purdue University, 2003a. p. 101-130. 